\title{
Infant Feeding Practices in Kaski District, Pokhara
}

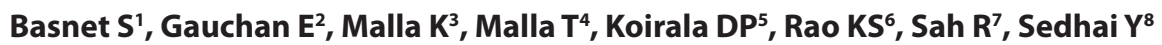 \\ ${ }^{1}$ Dr. Sahisnuta Basnet, MBBS, MD, Lecturer, ${ }^{2}$ Dr. Eva Gauchan, MBBS, MD, Lecturer, ${ }^{3}$ Dr. Kalpana Malla, MBBS, MD, Associate \\ Professor, ${ }^{4}$ Dr. Tejesh Malla, MBBS, MD, Associate Professor, ${ }^{5}$ Dr. Deepak P. Koirala, MBBS, MD, Lecturer, ${ }^{6}$ Dr. K. Sheshagiri \\ Rao, MBBS, MD, Professor and HOD Paediatrics, ${ }^{7}$ Dr. Ravi Sah, MBBS, Intern, ${ }^{8}$ Dr. Yuvraj Sedai, MBBS, Intern. All from \\ Department of Paediatrics, Manipal Teaching Hospital, Pokhara. Affiliated to Kathmandu University, Dhulikhel, Nepal
}

Address for correspondence: Dr. Sahisnuta Basnet, E-mail: sahisb@hotmail.com

\begin{abstract}
Introduction: Children in developing countries are prone to infectious diseases due to insufficient and inappropriate feeding practices. Socio-demographic and socio-economic factors directly and indirectly play a role in influencing infant feeding practices. This study was conducted to assess the sociodemographic and economic factors associated with initiation of breastfeeding, complimentary feeding, and the various prelacteal feeds practiced in Kaski, Pokhara. Materials and Methods: In this prospective study, interviews were conducted to 500 mothers at Manipal Teaching Hospital who brought their child for treatment. The interviews were conducted in a questionnaire format relating to their demographic and financial statuses. Results: A total of 500 mothers were questioned, out of which $86.6 \%$ gave their child breastmilk as its first food. $47 \%$ initiated breastfeeding within half an hour of child's birth. $86 \%$ gave Jaulo as the first complementary food to their children. About $26 \%$ of the mothers gave complementary feeding to their children before the recommended time of 6 months. Conclusion: Initiation of breastfeeding after life and complementary feeding practices overall has improved from previous studies. There is still need of making awareness campaigns and such in order to further improve this trend.
\end{abstract}

Key words: Breastfeeding, Complimentary feeding, Malnourishment

\section{Introduction}

$\mathrm{M}$ alnourishment is a major concern in developing countries. The cause of malnourishment is factored by many things including breastfeeding and complementary feeding practices. Children in developing countries are vulnerable to malnutrition because of low dietary intake, infectious diseases, lack of appropriate healthcare, and irregular feeding practices ${ }^{1}$.

Breastfeeding and complementary feeding practices is what provides adequate nutritional requirement for a child. WHO (World Health Organization) has specifically recommended exclusive breastfeeding for the first 6 months of child's life, and continue it for upto 24 months along with appropriate complementary feeding ${ }^{2}$. The mother's milk alone is sufficient for the first six months because it protects against harmful diseases and malnutrition. Exclusive breastfeeding can prevent deaths from infections and hypothermia ${ }^{3}$.

What is complementary feeding and why is it important? Complementary feeding is the stage where infants are fed actual food. This varies by region, countries and people. After the child's growth over 6 months, just breast milk is not sufficient for the growth and development of the baby, hence complementary feeding should be started. Irregular feeding practices during this stage are where most malnutrition occurs. It is important because of two key reasons, first, for nutritional growth and development and secondly to accustom them to eating habits of families and community ${ }^{4}$.

Keeping all these points in mind, this present study was conducted to see complementary feeding practice based on socio-demographic, socio-economic status, sex of child correlating to feeding practices and initiation of breastfeeding.

\section{Materials and Methods}

This was a prospective study carried out in Manipal Teaching Hospital between April 2010 to March 2011. A questionnaire survey was conducted at the hospital with 500 subjects who had brought their child for treatment. 
Every mother-child duo was interviewed and only those with very ill children were excluded from this study. Prior to questioning, the subjects were explained and sought for consent for the study.

Information such as mother's age, occupation, education, sex of the child brought for treatment, first solid food given, timing when breastfeeding was initiated, first complementary feeding, exact complementary feeding time and family income were probed to the subjects for the study. Analysis was done using Epi Info 3.5.3, and all significant statistical information was used for this study.

\section{Results}

Out of the surveyed 500 mothers, 263 of them fell under the 26-35 age range followed by 192 in 18-25 age range. There were none in the under 18 category (Table 1). 192 mothers had some education between grades 5-10. There were 99 mothers who had no education at all. Seventy-eight had education upto intermediate level and 62 had Bachelors degree or above. Mothers' education was a focal factor in this study, where it had direct relationship with complementary feeding time (Table 2). Out of the 500 mothers, 317 were housewives, whereas there were 97 in the agricultural occupation and 86 were job holders; 293 of the children were male and 207 female. $86.6 \%$ (433 subjects) gave the infants breastmilk as its first food, $7.6 \%$ (38) gave lactogen, $3.6 \%$ (18) gave honey and $1.6 \%$ (8) gave ghee (Figure 1). Almost half (235) initiated breastfeeding within half an hour of the birth of the infant (Table 3). $86 \%$ (430) gave Jaulo (Rice and Lentils mixed) as the first complementary food, 7\% (35) gave bananas, 28 (5.6\%) gave litto, and $7(1.4 \%)$ gave cerelac (Figure 2). Family income was another factor looked in this study which determined the pattern of feeding. 155 subjects fell in the Rupees 15000-24999 category, followed by 140 in the Rupees 10000-14999 range and 132 in Rupees 5000-9999 range (Table 4). Complementary feeding had a mean of $5 \pm 1.93$ months, and its frequency was directly and indirectly related with the various socio-demographic and socioeconomic factors (Table 5).

Table 1: Frequency of Mother's Age

\begin{tabular}{|c|c|c|}
\hline Mothers Age & Frequency & $\%$ \\
\hline$<18$ & 0 & $0 \%$ \\
\hline $18-25$ & 192 & $38.40 \%$ \\
\hline $26-35$ & 263 & $52.60 \%$ \\
\hline $36-45$ & 43 & $8.60 \%$ \\
\hline$>45$ & 2 & $0.40 \%$ \\
\hline Total & $\mathbf{5 0 0}$ & $\mathbf{1 0 0 . 0 0} \%$ \\
\hline
\end{tabular}

Table 2: Exact complementary feeding time correlating to mother's education

\begin{tabular}{|c|c|c|c|c|c|}
\hline $\begin{array}{l}\text { Exact Complementary } \\
\text { Feeding Time }\end{array}$ & No Education & Education (0-5) & $\begin{array}{l}\text { Education } \\
(5-10)\end{array}$ & $\begin{array}{c}\text { Education } \\
\text { (Intermediate) }\end{array}$ & $\begin{array}{c}\text { Education } \\
\text { (Bachelors and } \\
\text { Above) } \\
\end{array}$ \\
\hline 1 Month & 3 & 0 & 2 & 3 & 0 \\
\hline 1 and Half Month & 0 & 1 & 0 & 0 & 0 \\
\hline 2 Months & 14 & 5 & 10 & 10 & 2 \\
\hline 2 and Half months & 0 & 0 & 1 & 0 & 0 \\
\hline 3 Months & 11 & 4 & 19 & 6 & 4 \\
\hline 4 Months & 9 & 11 & 21 & 15 & 8 \\
\hline 5 Months & 24 & 13 & 50 & 22 & 21 \\
\hline 6 Months & 27 & 26 & 72 & 18 & 21 \\
\hline 7 Months & 2 & 6 & 6 & 2 & 2 \\
\hline 8 Months & 2 & 1 & 3 & 1 & 2 \\
\hline 9 Months & 2 & 1 & 2 & 1 & 0 \\
\hline 10 Months & 1 & 0 & 2 & 0 & 0 \\
\hline 1 Year & 3 & 1 & 4 & 0 & 2 \\
\hline 1 Year 4 Months & 1 & 0 & 0 & 0 & 0 \\
\hline
\end{tabular}


Table 3: Frequency of Exact Hour of Breastfeeding after life

\begin{tabular}{|l|c|c|}
\hline $\begin{array}{l}\text { Exact Hour Breastfed } \\
\text { after life }\end{array}$ & Frequency & Percent \\
\hline Half Hour & 235 & $47.00 \%$ \\
\hline 1 Hour & 144 & $28.80 \%$ \\
\hline 1 and Half Hour & 24 & $4.80 \%$ \\
\hline 2 Hours & 42 & $8.40 \%$ \\
\hline 2 and Half Hours & 1 & $0.20 \%$ \\
\hline 3 Hours & 3 & $0.60 \%$ \\
\hline 4 Hours & 6 & $1.20 \%$ \\
\hline 4 and Half Hours & 1 & $0.20 \%$ \\
\hline 5 Hours & 3 & $0.60 \%$ \\
\hline 6 Hours & 4 & $0.80 \%$ \\
\hline 10 Hours & 1 & $0.20 \%$ \\
\hline 12 Hours & 2 & $0.40 \%$ \\
\hline 18 hours & 1 & $0.20 \%$ \\
\hline 1 Day & 12 & $2.40 \%$ \\
\hline 1 and Half Day & 1 & $0.20 \%$ \\
\hline 2 Days & 20 & $4.00 \%$ \\
\hline Total & $\mathbf{5 0 0}$ & $\mathbf{1 0 0 . 0 0} \%$ \\
\hline
\end{tabular}

Table 5: Exact complementary feeding time and its frequency

\begin{tabular}{|l|c|c|}
\hline $\begin{array}{l}\text { Exact Complementary } \\
\text { Feeding time }\end{array}$ & Frequency & Percent \\
\hline 1 Month & 8 & $1.60 \%$ \\
\hline 1 and Half Month & 1 & $0.20 \%$ \\
\hline 2 Months & 41 & $8.20 \%$ \\
\hline 2 and Half months & 1 & $0.20 \%$ \\
\hline 3 Months & 44 & $8.80 \%$ \\
\hline 4 Months & 64 & $12.80 \%$ \\
\hline 5 Months & 130 & $26.00 \%$ \\
\hline 6 Months & 164 & $32.80 \%$ \\
\hline 7 Months & 18 & $3.60 \%$ \\
\hline 8 Months & 9 & $1.80 \%$ \\
\hline 9 Months & 6 & $1.20 \%$ \\
\hline 10 Months & 3 & $0.60 \%$ \\
\hline 1 Year & 10 & $2.00 \%$ \\
\hline 1 Year 4 Months & 1 & $0.20 \%$ \\
\hline Total & $\mathbf{5 0 0}$ & $\mathbf{1 0 0 . 0 0} \%$ \\
\hline
\end{tabular}

Table 4: Exact Complementary time in relation with mother's socio-economic status

\begin{tabular}{|c|c|c|c|c|c|c|}
\hline Exact CF time & $<$ Rs. 5000 & Rs. 5000-9999 & $\begin{array}{c}\text { Rs. } 10000- \\
14999 \\
\end{array}$ & $\begin{array}{c}\text { Rs. } 15000- \\
24999 \\
\end{array}$ & $\begin{array}{c}\text { Rs. } 25000- \\
50000\end{array}$ & > Rs. 50000 \\
\hline 1 Month & 0 & 2 & 1 & 4 & 1 & 0 \\
\hline 1 and Half Month & 0 & 0 & 0 & 1 & 0 & 0 \\
\hline 2 Months & 7 & 9 & 9 & 10 & 4 & 2 \\
\hline 2 and Half months & 1 & 0 & 0 & 0 & 0 & 0 \\
\hline 3 Months & 1 & 18 & 11 & 11 & 2 & 1 \\
\hline 4 Months & 1 & 19 & 16 & 21 & 7 & 0 \\
\hline 5 Months & 5 & 23 & 41 & 46 & 14 & 1 \\
\hline 6 Months & 6 & 45 & 53 & 48 & 10 & 2 \\
\hline 7 Months & 2 & 6 & 5 & 4 & 1 & 0 \\
\hline 8 Months & 0 & 2 & 1 & 4 & 1 & 1 \\
\hline 9 Months & 0 & 4 & 1 & 1 & 0 & 0 \\
\hline 10 Months & 0 & 1 & 0 & 1 & 0 & 1 \\
\hline 1 Year & 1 & 3 & 1 & 4 & 0 & 1 \\
\hline 1 Year 4 Months & 0 & 0 & 1 & 0 & 0 & 0 \\
\hline
\end{tabular}

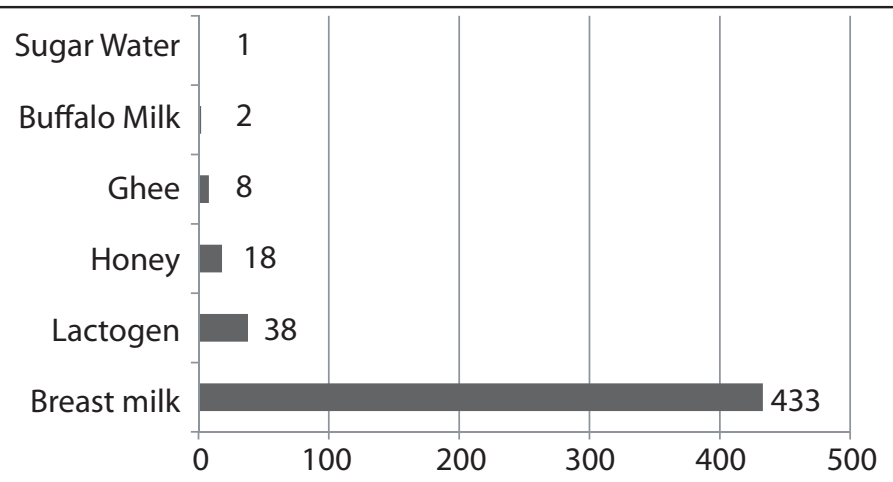

Fig 1: Frequency of first food given to child 


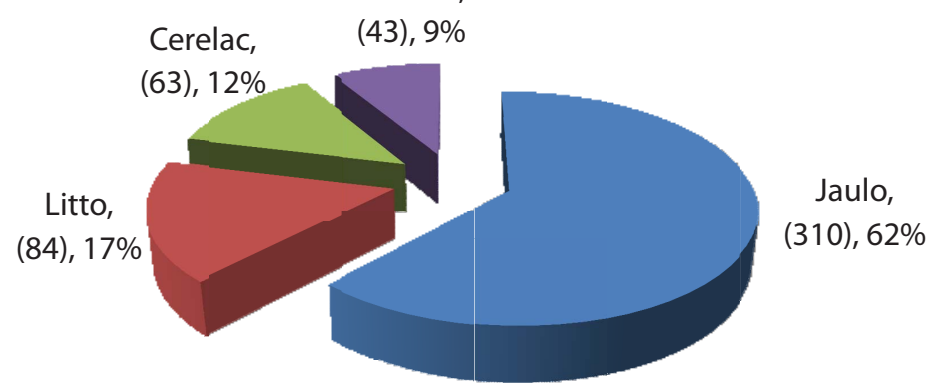

Fig 2: Pie diagram of various first food given to child

\section{Discussion}

This study examined the socio-economic and socio-demographic determinants of feeding practices in Nepal. The mean duration at which complementary feeding was started according to our study was 5 months. This is still below the WHO recommended 6 months, but is a significant improvement from previous study where it showed a mean of 4 months ${ }^{1}$. The introduction of early food such as water and unknown contaminated food can be infectious and is another major cause of malnutrition ${ }^{5}$. According to our study, $57.8 \%$ (289) gave complementary feeding prior to the WHO's recommended 6 months.

Just as in Subba's study, Jawlo (mushy mixture of rice and lentils) was the most popular of first food given to the child; in her study Jwalo and Daal/Bhat (42.8\%) was followed by Litho (27.1\%) and Ceralac $(21.4 \%)^{6}$. Our study had similar findings, where $62 \%$ (310) fed Jawlo, followed by litto $-16.4 \%$ (84) and Cerelac - 12.6\% (62). The fact that first food given to child is similar in most data across Nepal is due to the cultural and ethnical beliefs of the country ${ }^{7}$.

More than one in every three child is breastfed within the first hour of life. This is about $35 \%$ of the children surveyed by DHS, and in the same survey, $85 \%$ were breastfed by the end of the first day of life. Our study shows a huge improvement, as in this study $75.8 \%$ (379) initiated breastfeeding within a hour of the birth of their child, out of which $47 \%$ (235) had initiated within half an hour of life. By the end of first day, 95.8\% (479) had initiated breastfeeding. Early breastfeeding can benefit in reducing weight loss, raising blood glucose levels, lowering unconjugated bilirubin in the serum, reducing dehydration and leading to a more rapid return to birth weight ${ }^{8}$. This improvement and changes in mother's attitude towards initiation of breastfeeding can constitute to the fact that more awareness campaigns has significantly been increasing over time.

Socio-demographic features are key factors in determining the duration of when complementary food is instigated. Even though our mean of exact complementary feeding started was in the 5 month range, majority of our surveyed subjects had started complementary feeding at the age of 6 months. This finding can go hand in hand with the fact that according to Nepal's cultural beliefs, a child has to be fed rice or mushy rice (Jaulo), when he/she turns 6 months old? This might also be the major reason behind Jaulo being the most fed complementary food among our subjects.

Complementary feeding time and food vary by countries, for example in Mexico, complementary feedings are started as early as 1 month and as late as 8 months whereas by their cultural belief, tortillas, chicken, soft drinks and bread are some examples of first solid food given to child ${ }^{9}$. In our study, our complementary feeding time varied from 1 months to 16 months, and some of the first sold food given to child were Jaulo, Litto, Cerelac and Bananas. This stated fact does not correspond with the theory that developing countries tend to follow children feeding practices from developed countries ${ }^{10}$. The percentage of infants given Cerelac (formula) which in reality gives inadequate energy intake and can be prone to infections was reported at $16 \%$ by Manandhar et $\mathrm{al}^{11}$. Our study shows that only $12.6 \%$ of mothers have given cerelac to their children as first food. This is a significant improvement from other previous studies and shows better awareness among mothers.

$38 \%$ of mothers started complementary feeding at 6 months ${ }^{6}$. Our study shows 33\% of mothers started complementary feeding at 6 months. Though Subba's study subjects region are similar to our study, the decline in number might be because of the influxed number of candidates we interviewed. By 6 months, 77\% had started complementary feeding according to Subba's study, we have an improvement in this number where $91 \%$ of mothers had started complementary feeding, out of which $29 \%$ had started at 5 months. $22.6 \%$ had still not started complementary feeding by 7 months according to her article, whereas we have drastic improvement in that number, where only $5.6 \%$ had not 
started complementary feeding by the same amount of time.

Regarding mother's age and occupation, there wasn't much relating to the practice of complementary feeding and initiation of breastfeeding after life just as Paine et al stated in their article of feeding practice in Brazil. ${ }^{12}$ Mother's education however showed that the more the education, the better chances of complementary feeding being started at 6 months and breastfeeding initiated within the first hour.

Regarding Socio-economic status, it can be concluded that the lower the income, the more sporadically complementary feeding was initiated. This reasoning might be because of availability of finance among families in Nepal.

Correlating child'ssexwith initiation ofbreastfeeding and complementary feeding time, male children are more likely to be breastfed and complementary fed earlier than their female counterparts ${ }^{1}$. This statement is not true in our study as, male and female children were treated on a par, as breastfeeding was initiated by $88 \%$ on male children within the first 2 hours of life, whereas it was $89 \%$ on female children. As far as complementary feeding goes $59 \%$ of male children were given complementary feeding in the 5-6 month, whereas 57\% of female children were given complementary feeding in that same period. According to a religious and cultural belief, sons will be able to repay the mother's milk which he has been fed by his mother ${ }^{7}$. These kind of rational probably constituted in the result of DHS 2006, where male children are fed earlier and believed to be superior where their subjects were of a larger population of Nepal.

\section{Conclusion}

This study of infant feeding practice shows significant improvement in certain areas and detrimental in others. It does seem that mothers have become more aware of formulaic feeding and when initiation of complementary feeding and breastfeeding should be done. To see further improvement and this trend to grow over time, a thorough awareness programs by organizations and other campaigns in hospitals and similar institutions has to be made for mothers in rural Nepal.

\footnotetext{
Acknowledhements: Nil

Funding: Nil

Conflict of Interest: Nil

Permission from IRB: Yes
}

\section{References}

1. Ministry of Health and Population (MOHP) [Nepal], New ERA, and Macro International Inc. 2007. Nepal Demographic and Health Survey 2006. Kathmandu, Nepal: Ministry of Health and Population, New ERA, and Macro International Inc.

2. World Health Organization. Complementary feeding of young children in developing countries: A review of current scientific knowledge 1998, WHO/ NUT/98.1. Available from: www.who.int/nutrition/ publications/infantfeeding/WHO_NUT_98.1/en/ index.html

3. Negi K.S, Kandpal S.D. Breast Feeding Practices in Rural Area of District Dehradun, Uttaranchal. Indian J Prev Soc Med. 2004;35:183-88.

4. Palmer G. What is Complementary Feeding? International Baby Food Action Network (IBFAN) 2009. Available from: www.ibfan.org/art/IBFAN

5. Ministry of Health and Family Welfare, New Delhi. Exclusive breast-feeding. Government of India. CCSM Review 1993;7:1-2.

6. Subba S.H, Binu VS, Joshi HS et al. Infant practices of mothers in an urban area in Nepal. Kathmandu Univ Med J 2007;5:42-47.

7. Paneru S. Breast Feeding in Nepal: Religious and Culture Beliefs. CNAS Journal 1981; 3:43-52.

8. Davies, R.F. WHO Review of recent literature, Time of first feeding. MCH 1988;85:121-43.

9. Lipsky S, Stephenson PA, Koepsell TD et al. Breastfeeding and weaning practices in rural Mexico. Nutr Health 1994;9:255-63.

10. The prevalence and duration of breast-feeding: a critical review of available information. Division of Family Health World Health Organization. World Health Stat Q 1982; 35:92-116.

11. Manandhar K, Manandhar DS, Baral MR et al. One year follow up study of term babies born at Kathmandu medical college eaching hospital. Kathmandu Univ Med J 2004; 2:286-90.

12. Paine P. Dorea J.G. Gender role attitudes and other determinants of breast feeding intentions in Brazilian women. Child: Care, Health and Development 2001;27:27-61.

\section{How to cite this article?}

Basnet S, Gauchan E, Malla K, Malla T, Koirala DP, Rao KS, Sah R, Sedhai Y. Infant Feeding Practices in Kaski District, Pokhara. J Nepal Paediatr Soc 2012;32(1):23-27. 